ELK MOVEMENTS, HABITAT USE, AND POPULATION DYNAMICS IN THEODORE ROOSEVELT NATIONAL PARK

\author{
Lynn R. Irby \\ Clayton B. Marlow \\ Harold D. Picton \\ Jerry A. Westfall \\ Biology and Animal and Range Science Departments \\ Montana State University \\ Bozeman
}

Objectives

1. Description of daily and seasonal movements of elk (Cervus elaphus) ;

2. Identification of seasonally important habitat types and physiographic character of areas used for feeding, cover, mating, and calving;

3. Identification of damage to Park resources or property of adjoining landowners by elk;

4. Description of interactions between elk and other ungulates and identification of interactions that could detrimentally affect specific ungulate species;

5. Determination of human impacts on elk behavior and distribution in the Park; and

6. Description of elk age structure, productivity, and survivorship during 1987-88 and development of population goals that are consistent with Park management goals.

\title{
Methods
}

Habitat use patterns, movements, and population structure have been described through direct observation. A radiocollared animal was selected as a "target" and located using a radio receiver and hand held directional antenna. Activities, movement distances, and habitat types occupied by the target animal and its associates were noted at 5-minute intervals for 1 to 4-hour periods. This procedure sacrificed independence of individual observations (with minimal significant autocorrelation in 1-hour blocks tested during 1985 for the first phase of this study) to increase efficiency of data collection and reduce disturbance of elk. Locations of other ungulate species were noted while searching for elk and when seen during observation of elk groups. 
Incidental information on elk distribution was collected from site investigations of elk sightings by tourists and residents of areas adjacent to Theodore Roosevelt National Park. A trail survey of feces distribution was conducted in summer 1988. The trail survey consisted of counts of elk fecal pellet groups on randomly selected trail segments throughout the Park and in areas adjacent to the Park boundary.

Vegetation measurements (canopy coverage, species composition, and vegetation utilization in 3 height strata and production estimates for specific browse species) were made in summer-fall 1988 on plots established in 1982-86 and in habitat types for which no production estimates were available. Plot data will be used to compare species composition and utilization differences in areas used by elk with areas in which elk use is absent or minimal.

Habitat use patterns and food habits information collected in this study and studies by Sullivan (1988) and Norland et al. (1985) will be used to identify overlaps in forage and habitat use among ungulate species in the Park. Estimates of plant productivity by species/genus by habitat type taken from the literature and our work in the Park will be incorporated with ungulate food habits and habitat use information to produce an approximation of optimun population levels for elk, mule deer Odocoileus hemionus), white-tailed deer (‥ virginianus), bison (Bison bison), and feral horses.

Results and Discussion

1. Movements and distribution

Since their introduction into the South Unit of TRNP in March 1985, elk have steadily increased their range within the Park. By summer 1988, a few elk were using areas west of the Little Missouri River, and pellet transects indicated some regular movement of elk in and out of the Park along the north boundary (Fig. 1).

Five reports of elk outside TRNP were received in 1987-88. Three reports ( 1 cow herd and 1 bull near the east boundary and 2 bulls at distances of $160-475 \mathrm{~km}$ east of the Park) involved transplanted elk that returned to the Park. Two reports ( 18 and $50 \mathrm{~km}$ east of the Park) could have involved animals from a 1979 release of elk $150 \mathrm{~km}$ north of the South Unit.

Females, yearlings, and calves were organized in small (1-10 animals) groups in June but coalesced into 1 large group by late July in 1987 and 1988. Cow-calf groups were dispersed in the southeasterly quarter of the Park in early sumner 1987 but tended to concentrate along the southern boundary in late summer. Cow herds made much greater use of the central portion of the Park inside the Loop Road (Fig. 1) during sumner 1988 despite drought conditions and limited surface water in the area. Males were organized into small groups and occupied areas to the 


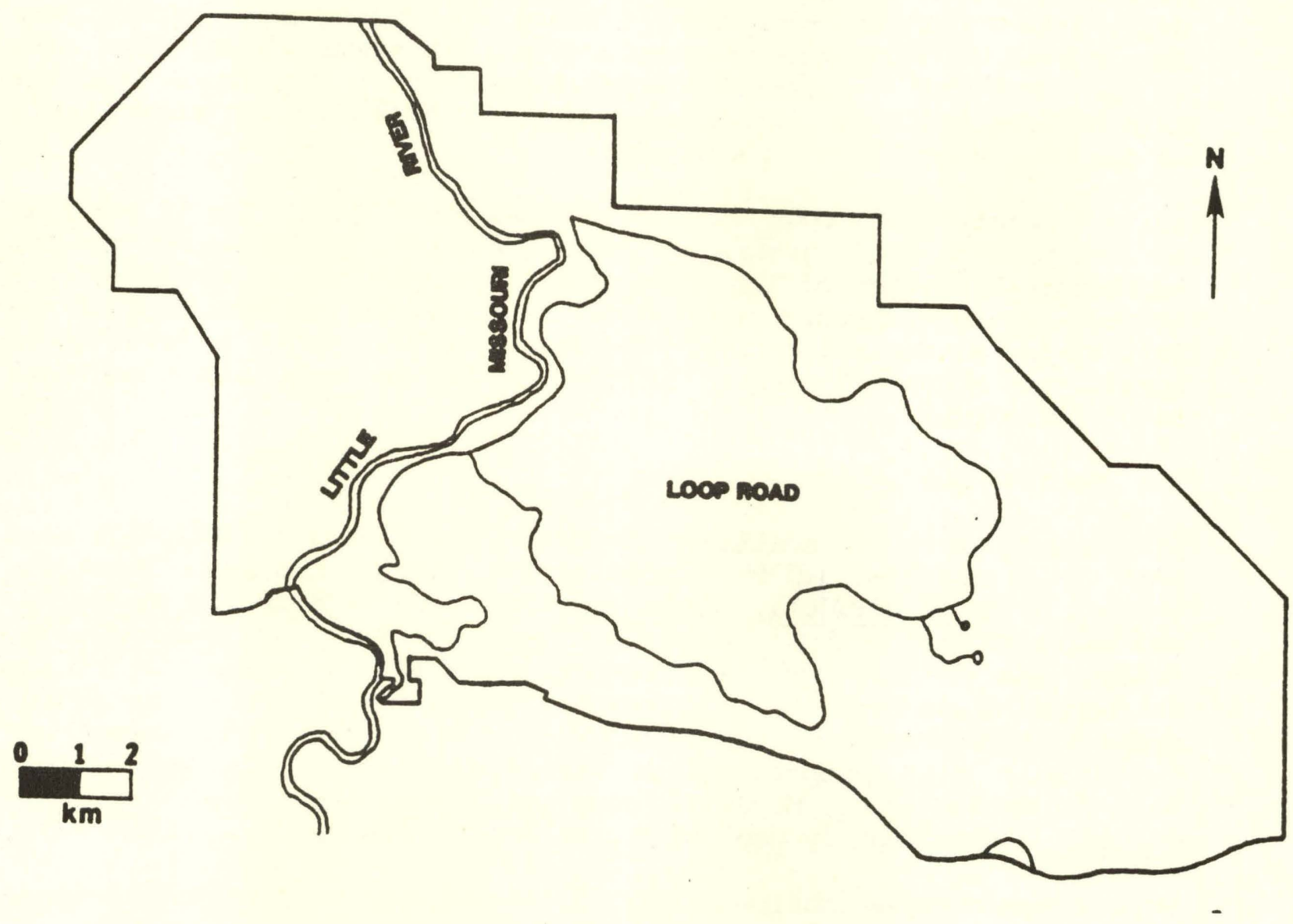

Figure 1. South Unit of Theodore Roosevelt National Park. 
north of the cow herds during the 1987 and 1988 summers.

Although single adult bulls occasionally associated with the large cowcalf group in mid summer, bull groups remained segregated from cow herds until late August or September. During the September - October rut, most elk in the Park were congregated along the eastern boundary plateau in 1987 and 1988. Successful separation of small cow bands from the main herd by bulls was not widespread until 1988 when the oldest bulls in the Park were $51 / 2$ years of age.

Bulls separated from cows in October - November 1987. The 12 yearling males joined bull groups in March-April. Bulls moved to the northcentral portion of the Park where they remained in groups of 1-9 through spring. Females moved widely through the eastern half of the Park during winter and spring. The large cow herd began to break up in April, and maximum dispersal occurred in May as cows sought secluded sites for calving.

\section{Habitat use}

Of the habitat types available in TRNP (Marlow et al. 1984), elk were most often observed in Introduced Grass, Scoria Complexes, Agropyron smithii - Stipa viridula, Juniperus scopulorum - Oryzopsis mircantha, Hardwood Draws, and Artemisia tridentata - Atriplex confertifolia. Feeding was concentrated in grassland types with heaviest use of the Introduced Grass type (A. cristatum and Bromus inermis) in early spring, types with abundant cool season grasses in winter and early sumer, and types with high proportions of warm season grasses in mid to late summer. Wooded types, Hardwood Draws and Juniper scopulorum - Oryzopsis mircantha, were heavily used as diurnal rest sites during warm weather.

Physiographic types (Marlow et al. 1984) used most heavily during summer 1987 were Upland Grassland and Scoria Hills. During winter 1987-88, elk fed in Upland and Lowland grasslands and rested in Breaks or Scoria types. Use of tree stands within Scoria and Breaks areas was much higher in summer than in winter.

The basic pattern of habitat use (grasslands for feeding, wooded sites for summer rest periods, and more open sites for winter rest periods) remained the same between 1985-87 and 1987-88, but use of some physiographic types changed. Use of Breaks declined and use of Upland Grassland increased in summer (Table 1). In winter, use of Grass Flats and Scoria Hills declined while use of Upland Grassland increased.

\section{Identification of damages}

We will be unable to assess changes in vegetation associated with elk use until the vegetation plot data has been analyzed. No damage complaints were filed in the 5 reports of elk outside the Park during 1987-88. 
Table 1. Physiographic type use ( $\%$ ) by elk in TRNP. Data from 1985-87 (Sullivan 1988) and summer 1987 were based on cow (>80\% of observations) and bull herds. The winter 1987-88 observations include only those froin cow herds. Numbers of elk-minutes on which percentages were based are given in the table.

\begin{tabular}{|c|c|c|c|c|}
\hline \multirow[b]{2}{*}{ Type } & \multicolumn{2}{|c|}{$1985-87$} & \multicolumn{2}{|c|}{$1987-88$} \\
\hline & $\begin{array}{l}\text { Surmer } \\
\text { (23285) }\end{array}$ & $\begin{array}{l}\text { Winter } \\
\text { (10777) }\end{array}$ & $\begin{array}{l}\text { Summer } \\
\text { (21361) }\end{array}$ & $\begin{array}{l}\text { Winter } \\
\text { (20971) }\end{array}$ \\
\hline Grass flats & 14 & 41 & 7 & 15 \\
\hline Breaks & 52 & 19 & 21 & 17 \\
\hline Ridge and ravine & 5 & 3 & & 9 \\
\hline Prairie dog town & 2 & $t^{a}$ & & \\
\hline Upland grassland & 20 & 10 & 40 & 41 \\
\hline Scoria hills & 8 & 28 & 32 & 18 \\
\hline Sagebrush bottoms & $t$ & & $t$ & \\
\hline
\end{tabular}

a Use $<18$ 


\section{Interactions between elk and other ungulates}

Overt interactions between elk and other ungulates were rare. Elk did tend to move away from bison and horses. Single mule deer adopted submissive postures when in proximity to elk, but larger groups of deer were observed feeding through elk herds with no hindrance from elk. Elk habitat use was most similar to that of mule deer. Bison and feral horses used some grassland sites favored by elk but made little use habitat types in broken terrain that elk used extensively. White-tailed deer were seldom seen in habitat utilized by elk.

\section{Human impacts}

All elk groups used isolated areas of the Park more frequently than areas which were easily accessible to tourists. When humans on foot or horseback were encountered, elk always moved away, usually running $1 / 2$ kilometer or more. Elk habituated to vehicles on the interstate highway and a county road along the east boundary of the Park during 1985-86. During 1988, tourists and park staff reported a few instances of elk remaining stationary when vehicles passed them on internal roads. Vehicles stopping within $500 \mathrm{~m}$ on any road elicited flight.

\section{Population dynamics and management goals}

Little mortality has occurred since introduction of elk into TRNP. One radiocollared bull disappeared from private land south of TRNP in 1986. One cow may have died following an injury in spring 1987. One bull was found dead in a sinkhole in spring 1988. The minimum population estimate for August 1988, 148 animals ('Table 2), is near the projected carrying capacity determined by Sullivan (1988). The calf:cow ratio in 1988 (53:100) was slightly lower than in 1987 (62:100) and 1986 $(60: 100)$.

The high calf production (73\% and $70 \%$ of females 2 years and older evidently produced calves that survived through summer in 1987 and 1988, respectively), high calf survival to 1 year, and the rapid development of antlers in males (most 3-year-olds produced antlers with 5-6 points) indicate a healthy productive herd which has not encountered major problems with forage quality or quantity.

\section{Conclusions}

During the 4 years since elk were introduced into TRNP, the population has increased in numbers, range, and, to a lesser extent, observability by visitors in the Park. Problems with elk condition/health, competition with other ungulates, and damage to adjoining farms have not developed despite the drought and high bison numbers in 1988. Data we collect and the model of optimuin population levels that will be constructed during this project should help Park staff effectively manage problems as they occur.

$$
-168-
$$


Table 2. Minimum number of elk in or adjacent to Theodore Roosevelt National Park determined from counts in August - September 1985-88.

\begin{tabular}{lccccc}
\hline Age/sex class & $\begin{array}{c}\text { Transplant } \\
\text { (Mar 1985) }\end{array}$ & 1985 & 1986 & 1987 & 1988 \\
\hline Females > 1 yr & 36 & 38 & 42 & 53 & $\mathrm{a}$ \\
Males > 1 yr & 8 & 9 & 15 & 25 & $\mathrm{a}$ \\
Calves & 3 & 17 & 25 & 33 & 37 \\
Total & 47 & 64 & 82 & 111 & 148 \\
\hline
\end{tabular}

a To be determined from autum/winter surveys. 


\section{Literature Cited}

Marlow, C. B., L. R. Irby, and J. E. Norland. 1984. Optimum carrying capacity for bison in Theodore Roosevelt National Park. Final Rep. Nat. Park Serv., Denver. MI State Univ., Bozeman.

Norland, J. E., L. R. Irby, and C. B. Marlow. 1985. Deternination of optimum bison stocking rate in Theodore Roosevelt National Park, North Dakota. J. Environ. Manage. 21:225-239.

Sullivan, M. G. 1988. Distribution, habitat use, and food habits of reintroduced elk in Theodore Roosevelt National Park, North Dakota. M.S. Thesis, Mr State Univ., Bozeman. 94 pp. 